\title{
A natureza das lesões traumáticas ocasionadas pela violência física em pacientes atendidos em serviço de emergência de um hospital público
}

Conhecer a natureza das lesões traumáticas ocasionadas pela violência física foi o objetivo desta pesquisa exploratória descritiva quantitativa, realizada no Hospital Cristo Redentor, Rio Grande do Sul. O universo da pesquisa foram 384 boletins de atendimento dos pacientes vítimas de violência física, com idade igual ou superior a 18 anos, nos meses de março e abril de 2010. Efetivou-se uma coleta de dados retrospectiva documental nos boletins de atendimento do serviço de emergência. Como resultado, identificamos que, dos pacientes atendidos, 134 (34,9\%) apresentaram corte/perfuração/laceração, 74 (19,3\%), fratura, e 49 (12,8\%), contusão/edema. Os atendimentos em que não houve lesões significativas corresponderam a 75 pacientes (19,5\%). Como alternativa de enfrentamento do problema, sugere-se a implantação de protocolos e sistemas de informação específicos, visando a orientar o desenvolvimento de medidas preventivas efetivas e de intervenção, a serem trabalhadas com o objetivo de reduzir tais agravos, bem como campanhas de conscientização, incentivando a população a notificar os casos.

Descritores: Violência, Epidemiologia, Morbidade, Lesões.

\section{The nature of traumatic injuries caused by physical violence in patients treated in the emergency room of a public hospital} Knowing the nature of traumatic injuries caused by physical violence was the purpose of this descriptive exploratory quantitative approach performed at Hospital Cristo Redentor, Rio Grande do Sul. The universe of the research were 384 reports of care of patients suffering from physical violence, aged 18 or more, over the months of March and April 2010. The retrospective documental data collection was implemented in the bulletins of the emergency service. We observed that the patients attended, 134 (34.9\%) had cut/puncture/laceration, 74 (19.3\%) fractures, 49 (12.8\%) injury/edema. Attendances where there were no significant lesions represented 75 patients (19.5\%). As an alternative to confronting the problem, we suggest the deployment of protocols and specific information systems, aiming to guide the development of effective preventative and intervention measures to be worked in order to reduce such injuries, as well as awareness campaigns, urging people for the reporting of cases.

Descriptors: Violence, Epidemiology, Morbidity, Injuries.

La naturaleza de las lesiones traumáticas causadas por la violencia física en los pacientes tratados en la sala de urgencias de un hospital público

Conocer la naturaleza de las lesiones traumáticas ocasionadas por la violencia física fue el objetivo de este estudio exploratorio descriptivo cuantitativo, realizado en el Hospital Cristo Redentor, Rio Grande do Sul. Lo universo investigado fue constituida de 384 boletines de atendimiento a pacientes víctimas de violencia física, con edad igual o superior a 18 años, durante los meses de marzo y abril del 2010. La colecta de datos retrospectiva y documental fue efectivada en los boletines de atendimiento del servicio de emergencia. Como resultado, identificamos que de los pacientes atendidos, 134 (34,9\%) presentaron corte/perforación/laceración, 74 (19,3\%) fractura, 49 (12,8\%) contusión/edema. Los atendimientos en que no hubo lesiones significativas correspondieron a 75 pacientes (19,5\%). Como alternativa para enfrentar el problema estudiado, se sugiere la implantación de protocolos y sistemas de información específicos, con el objetivo de orientar el desarrollo de medidas preventivas efectivas y de intervención para ser implementadas con la finalidad de reducir esos agravantes, así como campañas de concientización, incentivando a la población para la denuncia de los casos.

Descriptores: Violencia, Epidemiología, Morbidez, Lesiones.

\section{INTRODUÇÃO}

A tualmente, a violência vem sendo reconhecida não só como uma questão social ${ }^{(1)}$, mas como um problema de saúde pública ${ }^{(1-2-3-4-5-6)}$, pois acomete a população em grandes proporções, assumindo destaque na morbimortalidade do país ${ }^{(1-2-3,5,7-8-}$

9). No Brasil e no mundo, configura o quadro dos principais problemas de saúde, juntamente com as doenças crônicas e degenerativas ${ }^{(10)}$.

Segundo relatório sobre violência e saúde da Organização Mundial da Saúde (OMS), mais de 1 milhão de pessoas perdem a vida em decorrência de causas violentas todo ano ${ }^{(10-11)}$.

A partir da década de 1980, no Brasil, o setor de saúde passou

1 Enfermeira especialista em enfermagem de saúde pública - UFRGS.

2 Enfermeira. Doutora em gerontologia biomédica. Professora adjunta da Universidade Federal do Rio Grande do Sul. E-mail: mar.u@terra.com.br 
a preocupar-se com a problemática da violência, incluindo o tema nas agendas políticas e no campo programático da saúde $^{(10)}$. Em 1990, a violência começou a ser discutida pela Organização Mundial da Saúde em específico, separadamente das causas externas ${ }^{(10)}$. Em 2001, surgiram políticas voltadas para a temática com a publicação da portaria no $737 / 2001^{(12)}$, que busca promover a redução de morbimortalidade por acidentes e violência através de ações articuladas e sistematizadas $^{(2)}$. Outras contribuições surgiram através do Ministério da Saúde, como ficha de notificação obrigatória de profissionais de saúde perante suspeita ou confirmação de maus-tratos a crianças e adolescentes (portaria $n^{\circ}$ 1968/2001), registro e preenchimento sobre autorização de internação hospitalar de causas externas (portaria $n^{\circ}$ 1969/2001) e portarias no 969 e 970/2002, que dispõem sobre a qualidade de captar aqueles advindos de acidentes e violência ${ }^{(10)}$. Mais recentemente, em 2006, o Ministério da Saúde, a partir de experiências internacionais, implantou o sistema de Vigilância de Violência e Acidentes (Viva) ${ }^{(13)}$.

Contempladas na categoria denominada pela Classificação Internacional de Doenças (CID) como "causas externas" $(2,10)$, lesões, traumas e mortes causados por violência e acidentes são responsáveis por repercussões na saúde individual e coletiva, gerando custos emocionais e sociais elevados ${ }^{(10)}$.

Segundo a OMS, violência é definida como o uso de força física ou de poder, real ou por ameaça, contra si próprio ou outra pessoa, contra grupo ou comunidade, que resulte ou tenha qualquer possibilidade de resultar em lesão, morte, dano psicológico, deficiência de desenvolvimento ou privação ${ }^{(1,4,13)}$. Pode ser classificada segundo a tipologia proposta pela OMS como abuso físico, sexual, psicológico ou emocional e negligência ${ }^{(13)}$.

A violência física compreende atos violentos com uso de força física intencional, não acidental, com o objetivo de ferir, lesar ou destruir a pessoa, deixando ou não marcas evidentes em seu corpo. Manifesta-se através de tapas, beliscões, chutes, empurrões, arremessos de objetos, estrangulamentos, queimaduras, perfurações, mutilações, entre outras ações ${ }^{(14)}$.

Dados publicados pelo Ministério da Saúde em 2005, sobre a população brasileira, mostram que as agressões foram responsáveis por 52,5 óbitos por 100 mil habitantes ${ }^{(15)}$, estando contempladas entre as principais subcausas associadas a óbito por motivos externos ${ }^{(5)}$. Indicadores epidemiológicos e criminais apontam que, no Brasil, a violência social tem apresentado elevada magnitude e intensidade ${ }^{(7)}$. Nos principais centros urbanos, as taxas de mortalidade por causas violentas estão entre as mais altas do continente americano ${ }^{(7)}$.

Na maioria dos países, o conhecimento das causas externas e seu impacto é feito por meio de dados de mortalidade, sendo pouco conhecidos dados relacionados à morbidade hospitalar ${ }^{(14)}$. O serviço de emergência é, na maioria das vezes, a porta de entrada do serviço público, constituindo-se um importante indicador de violência, não raras vezes um dos únicos momentos de declaração da violência ocorrida(16)

O tema violência tenta consolidar-se no campo da saúde coletiva, e sua prevenção impõe esforços, como superar a noção de fatalidade e inevitabilidade, ultrapassando a noção de problema social ${ }^{(16)}$. O foco da saúde pública é oferecer o máximo de benefício ao maior número de pessoas, evitando problemas de saúde e expandindo uma assistência mais segura à população ${ }^{(11)}$. Discutir a prevenção da violência tem se tornado um complicador para as organizações de saúde, impondo novas práticas e novos aprendizados ${ }^{(16)}$.

A motivação que impulsionou a realização desta pesquisa está relacionada à atuação em um serviço de emergência de um grande hospital público de Porto Alegre, onde um elevado número de pacientes vítimas de violência procura atendimento hospitalar. Assim, a realização deste estudo visa a averiguar as principais lesões oriundas da violência física encontradas nesses atendimentos. Coloca-se como situação problema da presente pesquisa: qual a natureza das lesões traumáticas sofridas pelos pacientes vítimas de violência física, atendidos em um serviço de emergência de um hospital público?

Esta pesquisa teve como objetivo conhecer a natureza das lesões traumáticas ocasionadas pela violência física nos pacientes atendidos em um serviço de emergência de um hospital público de Porto Alegre, RS.

\section{METODOLOGIA}

O método usado para este trabalho foi a pesquisa exploratória descritiva com abordagem quantitativa. Essa tipologia permite realizar uma investigação do tema em estudo, identificando os fatores a ele relacionados e permitindo descrever a realidade encontrada $^{(17)}$. A abordagem quantitativa possibilita mensurar as variáveis pesquisadas, apresentando os resultados de forma quantificada.

O campo de ação deste estudo foi o Hospital Cristo Redentor (HCR) de Porto Alegre (POA), Rio Grande do Sul$\mathrm{RS}$, com perfil de atendimento ao trauma, principalmente as vítimas de acidente, popularmente conhecido como prontosocorro da região norte de POA. É um dos quatro hospitais pertencentes ao Grupo Hospitalar Conceição (GHC), todos de grande porte e com atendimento exclusivo aos pacientes do Sistema Único de Saúde (SUS). O HCR possui 304 leitos; desses, 29 são da Unidade de Tratamento Intensivo e 22, do serviço de emergência, com foco no atendimento das especialidades de traumato-ortopedia, neurocirurgia, bucomaxilofacial, cirurgia plástica e queimados, cirurgia do trauma em geral, entre outros. Em 2010, realizou 136.168 consultas de emergência e 
registrou 7.169 internações hospitalares ${ }^{(18)}$.

Considerou-se como a população desta pesquisa os boletins de atendimento das vítimas de violência física, de ambos os sexos, que receberam atendimento nos turnos da manhã, tarde e noite no serviço de urgência e emergência do Hospital Cristo Redentor, em Porto Alegre, RS. Adotouse o procedimento de amostragem por conveniência, tendo sido incluídos neste estudo os boletins de atendimentos dos pacientes com idade igual ou superior a 18 anos, vítimas de violência física, atendidos nos meses de março e abril de 2010. Como critério de exclusão, optou-se por deixar de fora os menores de 18 anos. A população estudada totalizou 384 boletins de atendimento.

A coleta de dados ocorreu de forma retrospectiva e documental, nos boletins de atendimento do serviço de emergência, existentes no banco de dados do serviço de arquivo médico do $\mathrm{HCR}$, através de instrumento elaborado para a transcrição dos dados:

- data;

- sexo;

- idade, apresentada por intervalos: de 18 a 29 anos, de 30 a 39, de 40 a 49 e acima de 50 anos;

- procedência, representada por: Porto Alegre, região metropolitana, interior e litoral;

- turno de atendimento: dia subdividido em três horários: manhã (das 7 h01 às 13h), tarde (13h01 às 19h), noite (19h01 às $07 \mathrm{~h})$;

- meios de agressão, com as agressões divididas em: objeto penetrante, objeto cortante, objeto contundente, força corporal/espancamento, coronhada, queimadura e não especificado;

- tipo de arma, nos casos utilizados: se a lesão foi decorrente de arma de fogo ou arma branca;

- natureza da lesão, classificada em: corte/perfuração/ laceração; fratura; hematomas/escoriações; contusão/edema; lesão de órgãos internos do tórax e abdome; traumatismo cranioencefálico (consideraram-se como TCE as lesões em que ocorreram patologias neurocirúrgicas); queimadura e sem lesão (não foram percebidas lesões significativas);

- localização da lesão por segmento corpóreo: cabeça e pescoço; tronco (tórax, abdome, pelve e dorso); membros superiores e membros inferiores;

- especialidade médica envolvida nos atendimentos, com pacientes classificados conforme rotina hospitalar nas seguintes especialidades: emergencista (atendimento inicial, responsável pelo direcionamento às especialidades); traumatologia; neurocirurgia; cirurgia do trauma/geral; cirurgia plástica; bucomaxilofacial e cirurgia vascular;

- evolução do atendimento: alta hospitalar; observação; internação; bloco cirúrgico; evasão/fuga; termo de responsabilidade pela desistência do atendimento; retorno à origem (situações em que o hospital foi contatado para realizar uma avaliação em alguma das especialidades, havendo, após, condições de o paciente retornar ao serviço de saúde de origem); e óbito.

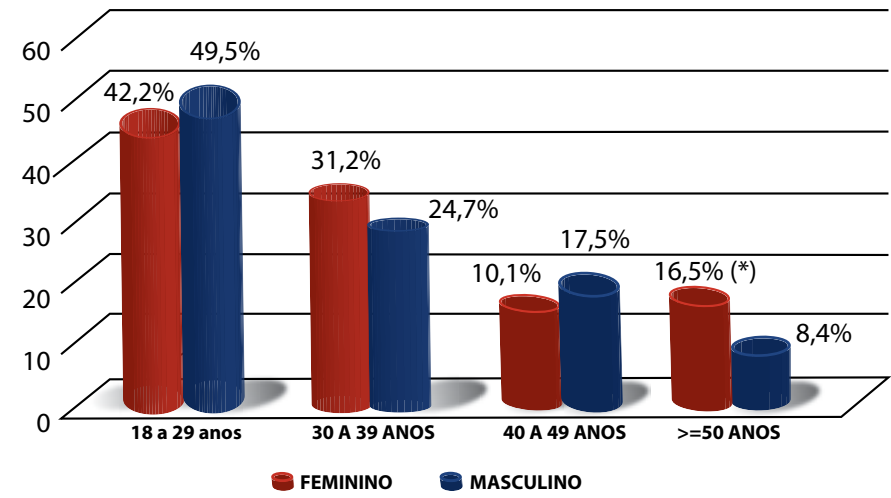

Figura 1- Distribuição da faixa etária segundo o sexo das vítimas de violência física atendidas no serviço de emergência do HCR, no período de março a abril de $2010(P=0,021)$.

$\left({ }^{*}\right)$ o número encontrado foi significativo estatisticamente.

A presente pesquisa teve a aprovação da Comissão de Pesquisa da Escola de Enfermagem da Universidade Federal do Rio Grande do Sul (Compesq) - com parecer favorável em 31 de janeiro de 2011, com registro sob o número 050/2010 - e do Comitê de Ética e Pesquisa do Grupo Hospitalar Conceição (CEP/GHC) - tendo o parecer favorável em 14 de janeiro de 2011, com registro sob o número 10-242.

Os dados foram tabulados e processados a partir do programa SPSS, versão 16.0, e analisados através de estatística descritiva, por meio de distribuição de frequências. As diferenças entre os gêneros foram mensuradas pelo teste de Qui-Quadrado de Pearson, com análise de resíduos ajustados, e apresentadas em gráficos. Adotou-se nível de significância de $5 \%(p<0,05)$. Os resultados foram discutidos com base no referencial teórico inerente ao tema. Neste trabalho, incluíramse apenas os registros de atendimento de violência física.

\section{ANÁLISE E DISCUSSÃO DOS RESULTADOS}

Dos atendimentos realizados pelo serviço de emergência do Hospital Cristo Redentor (HCR) em março e abril de 2010, 384 foram prestados às vítimas de violência física em pessoas com idade igual ou superior a 18 anos. $O$ período estudado revelou um número próximo de atendimentos/mês de 201 e 183, respectivamente.

Quanto à faixa etária das vítimas, a pesquisa identificou a oscilação entre 18 e 68 anos (observando critério de inclusão), com maior incidência entre 18 e 29 anos, seguido de 30 a 39 anos, para ambos os sexos, conforme apresenta a figura 1.

Esses dados vão ao encontro de uma pesquisa realizada pelo Ministério da Saúde (Sistema de Vigilância de Violência e Acidentes - Viva), apontando que as proporções maiores de atendimento por agressões e maus-tratos foram observadas em adolescentes e adultos jovens. Tanto no sexo masculino quanto no feminino, a faixa etária mais frequente incluiu pessoas de 20 a 29 anos, seguidas das de 30 a $39 \operatorname{anos}^{(14)}$. Em pesquisa realizada na mesma localidade, porém em 
outro hospital de referência em trauma, 59,4\% dos pacientes hospitalizados por violência tinham entre 20 e 39 anos(20). Estudo efetuado no serviço de emergência Alta Floresta, em 2006, confirma como faixa etária com maior percentual de atendimentos por agressão a de 20 a 39 anos $(56,3 \%)^{(21)}$. Em investigação quanto aos atendimentos de emergência por violência em serviços públicos de Teresina-Pl, a faixa

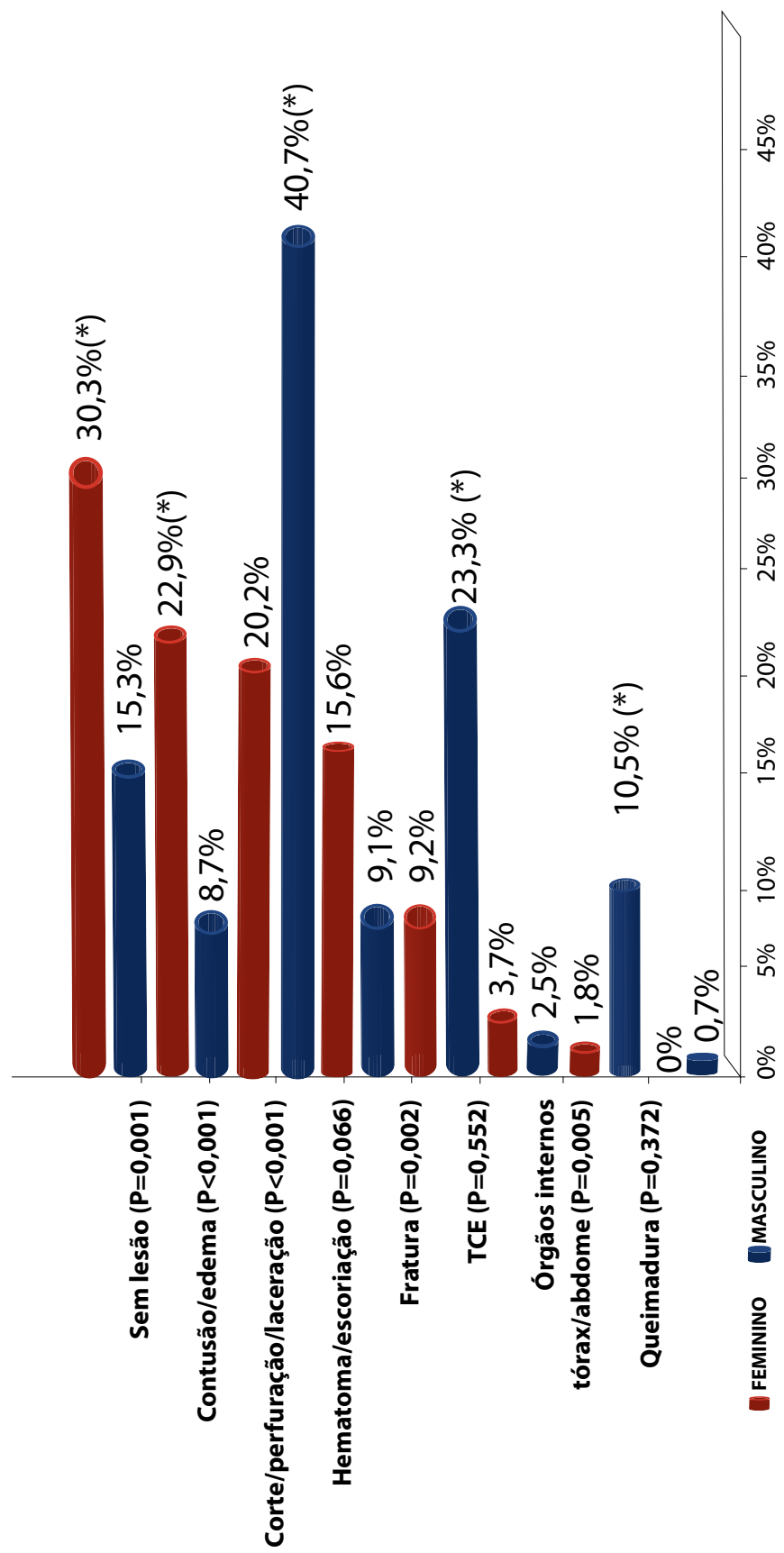

Figura 2 - Distribuição da natureza das lesões segundo o sexo das vítimas de violência física, atendidas no HCR, no período de março a abril de 2010.

(*) o número encontrado foi significativo estatisticamente. etária mais afetada foi a de 20 a 29 anos (40,9\%), seguida pela de 30 a 39 anos $(17,5 \%)^{(22)}$. Resultados encontrados em pesquisa realizada em Cuiabá-MT mostram que, das agressões ocorridas, as taxas mais elevadas encontravam-se nas faixas etárias de 20 a 29 anos (36,5\%) e 30 a 39 anos $(24,9 \%)^{(23)}$. Constata-se maior vulnerabilidade, morbidade e mortalidade em jovens, por causas externas, em especial pela violência(24).

A figura 1 mostra que, na faixa etária maior ou igual a 50 anos de idade, foi estatisticamente significativa a predominância da mulher nos atendimentos por violência física.

Pesquisa realizada em unidade de pronto atendimento em Pouso Alegre-MG identificou que, nas idades entre $40 \mathrm{e}$ 44 anos, houve um número superior de vítimas femininas, apontando diferenças na faixa etária mais acometida pelo sexo feminino ${ }^{(5)}$.

$\mathrm{Na}$ amostra estudada, evidenciou-se que $275(71,6 \%)$ dos pacientes atendidos eram do sexo masculino. Estudo do projeto Viva, do Ministério da Saúde, mostrou que, do total de atendimentos por agressões e maus-tratos, $75,7 \%$

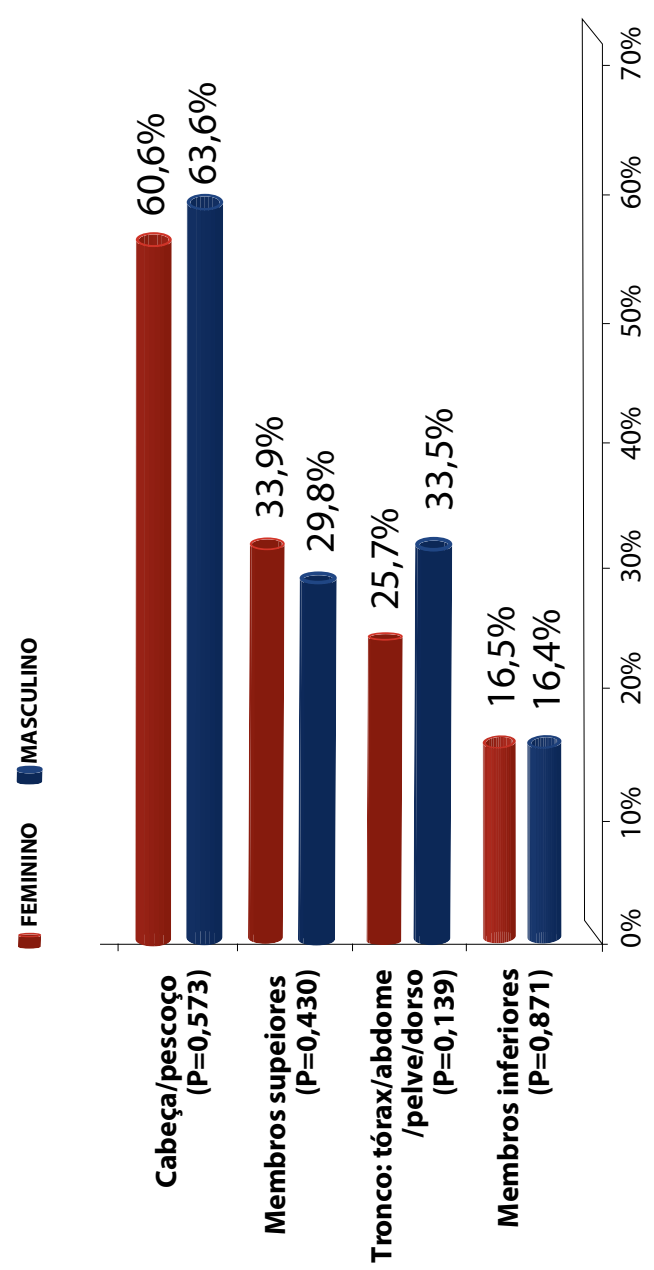

Figura 3 - Distribuição da localização das lesões por segmento corpóreo segundo o sexo das vítimas de violência física atendidas no HCR, no período de março a abril de 2010 
ocorreram entre homens ${ }^{(14)}$. Na pesquisa realizada no serviço de emergência de Alta Floresta, o sexo masculino obteve $81,3 \%$ dos atendimentos por agressão ${ }^{(21)}$. No estudo realizado com pacientes internados no Hospital de ProntoSocorro de Porto Alegre, 90,5\% representaram o gênero masculino ${ }^{(20)}$. Em Ribeirão Preto-SP, pesquisa realizada em um hospital universitário encontrou o sexo masculino como maioria entre as vítimas de violência, com um percentual de $93,3 \%{ }^{(3)}$. Os homens também representaram a maior proporção entre os atendimentos de emergência nos serviços públicos de Teresina-PI. Do total de vítimas de agressão/maus-tratos, 261 (76,1\%) eram do sexo masculino e, em comparação com as mulheres, apresentaram maior chances de sofrerem agressão física ${ }^{(22)}$. Estudo realizado em cinco unidades de urgência e emergência de Cuiabá-MT observou que a proporção de homens superou a de mulheres no que se refere a agressões em uma razão de sexo igual a $3,5^{(23)}$. As pesquisas citadas confirmam os resultados deste estudo, mostrando o sexo masculino com maior incidência de violência física, consequentemente, de maior ocorrência nos atendimentos prestados.

Quanto à procedência, 275 são da cidade de Porto Alegre $(71,6 \%)$ e 102 , da região metropolitana $(26,6 \%)$. Do interior e do litoral, identificaram-se números inexpressivos: cinco $(1,3 \%)$ e dois $(0,5 \%)$, respectivamente. Em pesquisa realizada em outro hospital de referência em trauma, na mesma localidade, com pacientes internados devido à violência, a maioria era procedente de Porto Alegre (59,54\%), confirmando o dado encontrado(20).

Analisando a distribuição dos atendimentos por hora de entrada, percebe-se que o turno da noite foi responsável por $223(58,1 \%)$. Os turnos da manhã e tarde apresentaram percentuais semelhantes, de $81(21,1 \%)$ e 80 (20,8\%), respectivamente. Em comparação a um estudo realizado com vítimas de causas externas, no município de Pouso Alegre-MG, identificaram-se diferenças: nesses atendimentos, a incidência de agressões foi igual para os turnos da tarde e noite, com uma concentração proporcional maior na madrugada ${ }^{(5)}$. Outra investigação, realizada em dois hospitais públicos de referência para o atendimento de emergência no Rio de Janeiro, também apontou diferenças, em que os plantões diurnos receberam demandas maiores de atendimentos por causas externas, com $71 \%$ no Hospital Municipal Salgado Filho e $69,6 \%$ no Hospital Municipal Miguel Couto. Foram observadas exceções nos fins de semana, quando os plantões noturnos foram os mais procurados ${ }^{(16)}$.

Com relação aos meios de agressão, 169 (44\%) não foram especificados, sendo apenas descritos como "agressão". Das agressões especificadas, 100 pacientes foram vitimados por objeto penetrante (26\%), seguidos de 27 por objeto cortante (7\%) e 19 por objeto contundente $(4,9 \%)$. O uso da força corporal/espancamento representou 59 pacientes $(15,4 \%)$, tendo menor escala as agressões por coronhada, com nove casos $(2,2 \%)$, e duas situações de queimadura $(0,5 \%)$. Nos casos em que foi utilizada arma, a pesquisa identificou: 93 feridos por arma de fogo (77,5\%) e 27 por arma branca (22,5\%).

Em estudo com pacientes internados no HPS de Porto Alegre citado anteriormente, $47,9 \%$ pessoas foram agredidas por arma de fogo, $26,5 \%$ por arma branca e $25 \%$ por agressão física ${ }^{(20)}$. Observou-se que a maioria das agressões também foi ocasionada por arma de fogo, porém com um percentual menor. Entre os feridos por arma branca, os dados foram semelhantes; com relação à agressão física, os números foram mais elevados. Cabe ressaltar que, na presente pesquisa, um grande número foi tratado como agressão em geral, não especificando a tipologia. Portanto, infere-se que, entre as agressões não especificadas, poderão existir aquelas ocasionadas pela força corporal, mas que não foram descritas como tal. Pesquisa já citada, realizada em uma unidade de pronto atendimento municipal de referência para urgência em Minas Gerais, indicou que as agressões foram a terceira mais importante causa de morbidade, o que correspondeu a 10,8\%

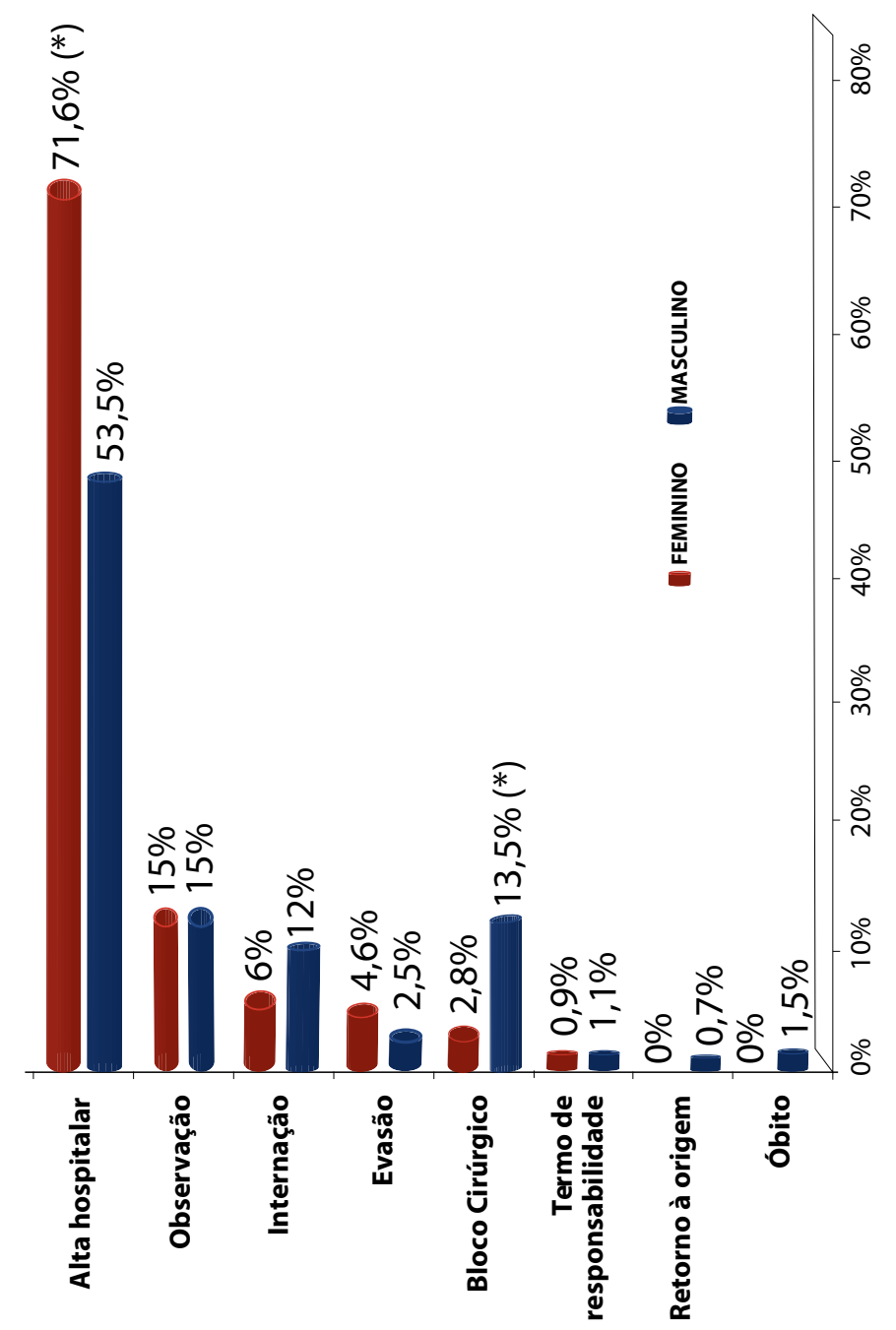

Figura 4 - Distribuição da evolução do atendimento segundo o sexo das vítimas de violência física atendidas no HCR, no período de março a abril de $2010(P=0,010)$.

${ }^{*}$ ) o número encontrado foi significativo estatisticamente. 
dos atendimentos. Desses, 34,1\% foram devido à força corporal, $31,7 \%$ por objeto cortante e $31,7 \%$ por objeto contundente ${ }^{(5)}$. Com relação aos meios de agressão registrados, percebeu-se que os percentuais foram mais elevados.

Ao comparar a natureza da lesão na amostra estudada, foram mais comuns os atendimentos em que a vítima apresentava cortes/perfuração/laceração (134 casos, ou 34,9\%), fratura (74 casos, ou 19,3\%), contusão/edema (49, ou 12,8\%) e lesão de órgãos internos de abdome e tórax (31, ou 8,1\%). Outros achados apontaram para: 42 situações de hematoma/ escoriação $(10,9 \%), 11$ de traumatismo cranioencefálico $(2,9 \%)$ e duas de queimadura $(0,5 \%)$. Os atendimentos em que não houve lesões significativas (denominados "sem lesão") corresponderam a 75 pacientes $(19,5 \%)$.

$\mathrm{Na}$ confrontação do sexo das vítimas, verificam-se, na figura 2 , diferenças estatisticamente significativas. Entre os homens, foram mais frequentes as lesões por corte/ perfuração/laceração (112, ou 40,7\%), fratura (64, ou $23,3 \%$ ) e lesão de órgãos internos do tórax e do abdome (29, ou $10,5 \%)$. Nas mulheres, as lesões mais acometidas foram por contusão e edema, com 25 casos (22,9\%). Nos atendimentos em que não ocorreram lesões significativas, o percentual maior também envolveu as mulheres (33 casos, ou 30,3\%). O projeto Viva, do Ministério da Saúde, mostrou como natureza da lesão mais frequente os cortes, seguidos de contusão e fratura, para ambos os sexos. Os atendimentos em que não ocorreram lesões significativas também foram mais comuns nas mulheres ${ }^{(14)}$.

No que se refere às partes do corpo lesadas, as mais atingidas foram: cabeça e pescoço, com 241 casos (62,8\%); tronco (abdome, tórax, pelve e dorso), com 120 (31,3\%); e membros superiores, com 119 (31\%); os membros inferiores representaram 63 ocorrências (16,4\%). Relacionando-se ao sexo, não houve diferenças estatisticamente significativas entre as partes do corpo (figura 3). O projeto Viva mostrou que cabeça e face $(49,6 \%)$, membros superiores $(31,4 \%)$, tórax e dorso $(18,2 \%)$ foram as partes mais acometidas em relação à localização da lesão(14). 0 estudo realizado em Alta Floresta, já referido, aponta que as agressões se destacaram como a violência que mais comprometeu as partes do corpo: $62,5 \%$ atingiram a cabeça, $18,8 \%$ o pescoço, $31,3 \%$ os membros superiores, $18,8 \%$ o tórax, $12,5 \%$ o abdome e $12,5 \%$ os membros inferiores ${ }^{(21)}$. Pesquisa realizada em Pouso Alegre mostra que, nas agressões, a cabeça e os membros superiores passam a ter grande importância $(37,3 \%$ e $34,3 \%$, respectivamente), por serem regiões bastante expostas a situações de violência - a cabeça, por ser visada pelo agressor, e os membros superiores, pela utilização de autodefesa ${ }^{(5)}$.

Quanto à distribuição dos especialistas envolvidos no atendimento das vítimas de violência física, a maioria foi cuidada por mais de um especialista - 297 (77,3\%).
O emergencista, responsável grande parte das vezes pelo atendimento inicial e pelo direcionamento às especialidades, respondeu por 306 atendimentos (32\%). Das especialidades, houve preponderância na demanda pelo traumatoortopedista, 148 (15,5\%), e pela cirurgia plástica, 146 (15,3\%). Logo após, com 122 atendimentos (12,8\%), a neurocirurgia, seguida pela cirurgia do trauma, com $98(10,3 \%)$, e cirurgia vascular, com 22 casos (2,3\%).

Comparando com a pesquisa realizada no Rio de Janeiro, já citada, houve divergência quanto ao número de especialistas envolvidos, pois, nesse trabalho, a maior parte foi cuidada por apenas um especialista. No que tange à especialidade prevalente, o ortopedista também foi quem prestou a maioria dos atendimentos ${ }^{(16)}$.

Quanto à evolução dos casos após o atendimento de emergência inicial, $225(58,6 \%)$ receberam alta, $57(14,8 \%)$ permaneceram em observação, $40(10,4 \%)$ tiveram como desfecho o bloco cirúrgico e 39 (10,2\%) evoluíram para a internação. Os desfechos relacionados à evasão hospitalar, ao termo de responsabilidade pela desistência do atendimento e ao retorno à origem perfizeram 19 atendimentos prestados (4,9\%). Dos pacientes que foram a óbito, todos os quatro (1\%) eram do sexo masculino e foram vitimados por arma de fogo.

A distribuição de homicídios em Porto Alegre mostra que a maioria das vítimas era do sexo masculino. Com relação às causas de morte, a arma de fogo foi o meio mais utilizado ${ }^{(25)}$. Nas unidades de urgência e emergência de Cuiabá-MT, citada anteriormente, das vítimas de causas externas, a maior taxa de mortalidade ocorreu nas agressões $(2,5 \%)$. O percentual das vítimas que receberam alta após o atendimento também foi maior $(90 \%)^{(23)}$.

Pesquisa do Ministério da Saúde encontrou como evolução dos casos a alta hospitalar $(52,1 \%)$ e a internação $(29,5 \%)$. Dos atendimentos realizados, os percentuais de óbitos e de fuga/ evasão foram de $1,8 \%$ e $1,5 \%$, respectivamente ${ }^{(14)}$. Percebemse semelhanças nos percentuais dos pacientes que tiveram como desfecho a alta hospitalar e o óbito.

\section{CONSIDERAÇÕES FINAIS}

Esta pesquisa permitiu conhecer a natureza das lesões traumáticas encontradas nos pacientes acometidos pela violência física, atendidos na emergência do HCR, nos meses de março e abril de 2010.

Referente ao preenchimento dos boletins de atendimento, de onde foram retiradas as informações utilizadas nesta pesquisa, constatou-se que a maioria estava completa; contudo, houve um número considerável de casos em que não foram especificados os meios de agressão, sendo apenas registrados como "agressão".

Mesmo abrangendo um curto período, porém com uma 
população considerável, ressalta-se a importância do estudo, já que revelou as características da morbidade hospitalar por violência física, o que inexistia para o local estudado.

Considera-se que, frequentemente, são priorizados os dados advindos da mortalidade de eventos violentos, tendo em vista a maior disponibilidade e a qualidade dos registros. No entanto, no que tange à definição de prioridades, as vítimas não fatais são consideradas importantes fontes de conhecimento da natureza e da magnitude do problema, oferecendo oportunidades para a compreensão e o controle das situações de violência.

Como alternativa de enfrentamento do problema, sugerese a implantação de protocolos e sistemas de informação específicos, visando a orientar o desenvolvimento de medidas preventivas efetivas e de intervenção - a serem trabalhadas com o intuito de reduzir tais agravos -, assim como campanhas de conscientização, incentivando a população a notificar os casos.

\section{Referências}

1. Schraiber LB, Oliveira AFPL, Couto MT. Violência e saúde: estudos científicos

recentes [Internet]. [citado 2011 Jun 20]. Disponível em: http://www.scielosp.org/ pdf/rsp/v40nspe/30630.pdf.

2. Guimarães JMX, Vasconcelos EE, Cunha RS, Melo RD, Pinto LF. Estudo epidemiológico da violência por arma branca no município de Porto Grande, Amapá [Internet]. [citado 2011 Jun 20]. Disponível em: http://www.scielo.br/pdf/ csc/v10n2/a22v10n2.pdf.

3. Robazzi MLCC, Silveira CA, Marziale MHP, Dalri MCB, Haas VJ, Alves LA. 0 prontuário hospitalar auxiliando na identificação da violência no trabalho [Internet]. [citado 2011 Jun 18]. Disponível em: http://www.facenf.uerj.br/v14n4/ v14n4a02.pdf.

4. Dahlberg LL, Krug EG. Violência: um problema global de saúde pública [Internet]. [citado 2011 Jun 20]. Disponível em: http://www.scielo.br/pdf/csc/ v11s0/a07v11s0.pdf.

5. Mesquita-Filho M, Mello-Jorge MHP. Características da morbidade por causas externas em serviço de urgência [Internet]. [citado 2011 Jun 10]. Disponível em: http://www.scielosp.org/pdf/rbepid/v10n4/15.pdf.

6. Minayo MCS, Deslandes SF. Análise da implantação da rede de atenção às vítimas de acidentes e violência segundo as diretrizes da Política Nacional de Redução da Morbimortalidade sobre Violência e Saúde [Internet]. [citado 2011 Jun 10]. Disponível em: http://portal.saude.gov.br/portal/arquivos/pdf/4artigo iniciativas_vig_prev_acidentes.pdf.

7. Souza ER, Lima MLC. Panorama da violência urbana no Brasil e suas capitais [Internet]. [citado 2011 Jun 10]. Disponível em: http://www.scielosp.org/pdf/csc/ v11s0/a11v11s0.pdf.

8. Deslandes SF, Lemos MP. Construção participativa de descritores para avaliação dos núcleos de prevenção de acidentes e violência, Brasil. Rev Pan-americana Saúde [Internet]. [citado 2011 Jun 15]. Disponível em: http://journal.paho.org/ uploads/1233083836.pdf.

9. Deslandes SF, Minayo MCS, Lima MLC. Atendimento de emergência às vítimas de acidentes e violências no Brasil [Internet]. [citado 2011 Jun 18]. Disponível em: http://www.bvsde.paho.org/bvsacd/cd68/atendimento.pdf.

10 Minayo MCS. A inclusão da violência na agenda da saúde: trajetória histórica [Internet]. [citado 2011 Jun 20]. Disponível em: http://www.scielo.br/pdf/csc/ v11s0/a15v11s0.pdf.

11. Organização Mundial da Saúde. Relatório mundial sobre violência e saúde. OMS: Genebra; 2002.

12. Ministério da Saúde (BR). Portaria $n^{\circ} 737 / 2001$, de 16 de maio de 2001. Política Nacional de Redução da Morbimortalidade por Acidentes e Violências [Internet]. [citado em 2011 Jun 08]. Disponível em: http://www.mp.rs.gov.br/infancia/ legislacao/id3072.htm.
13. Mascarenhas MDM, Malta DC, Silva MMA, Lima CM, Carvalho MGO, Oliveira VLA. Violência contra a criança: revelando o perfil dos atendimentos em serviços de emergência, Brasil, 2006 e 2007 [Internet]. [citado 2011 Jun 20]. Disponível em: http://www.scielosp.org/pdf/csp/v26n2/13.pdf.

14. Ministério da Saúde (BR). Secretaria de Vigilância em Saúde. Departamento de Análise de Situação de Saúde. Viva: vigilância de violências e acidentes, 2006 e 2007 [Internet]. [citado em 2011 Jun 15]. Disponível em: http://bvsms.saude.gov. br/bvs/publicacoes/viva_vigilancia_violencias_acidentes.pdf.

15. Ministério da Saúde (BR). Saúde Brasil 2007: uma análise da situação de saúde. Brasília: Ministério da Saúde; 2008.

16. Deslandes SF. O atendimento às vítimas de violência na emergência: prevenção em uma hora dessas? [Internet]. [citado 2011 Jun 28]. Disponível em: http://www.scielosp.org/pdf/csc/v4n1/7132.pdf.

17. Polit DF, Hungler BP. Fundamentos de pesquisa em enfermagem. $5^{\text {a }}$ ed. Porto Alegre: Artes Médicas; 2004.

18. Grupo Hospitalar Conceição. Hospital Cristo Redentor [Internet]. [citado 2011 Jun 10]. Disponível em: http://www.ghc.com.br/default. asp?idMenu=2\&idSubMenu=4.

19. Ministério da Saúde (BR). Conselho Nacional de Saúde. Resolução 196, de 10 de outubro de 1996: diretrizes e normas regulamentadoras de pesquisa envolvendo seres humanos. Brasília: Ministério da Saúde; 1996.

20. Leal SMC, Lopes MJM. A violência como objeto da assistência em um hospital de trauma: "o olhar" da enfermagem [Internet]. [citado 2011 Jul 02]. Disponível em: http://www.scielosp.org/pdf/csc/v10n2/a20v10n2.pdf.

21. Marchese VS, Scatena JHG, Ignotti E. Caracterização das vítimas de acidentes e violências atendidas em serviço de emergência. Município de Alta Floresta, MT (Brasil) [Internet]. [citado 2011 Jul 02]. Disponível em: http://www.scielo.br/pdf/ rbepid/v11n4/11.pdf.

22. Mascarenhas MDM, Pedrosa AAG. Atendimentos de emergência por violência em serviços públicos de Teresina, PI [Internet]. [citado 2011 Jun 28]. Disponível em: http://www.scielo.br/pdf/reben/v61n4/16.pdf.

23. Oliveira LR, Mello-Jorge MHP. Análise epidemiológica das causas externas em unidades de urgência e emergência em Cuiabá-Mato Grosso [Internet]. [citado 2011 Jun 28]. Disponível em: http://www.scielo.br/pdf/rbepid/v11n3/08.pdf. 24. Leal SMC. Violência como objeto da assistência em um hospital de trauma: o"o olhar" da enfermagem [Internet]. [citado em 2011 Jun 21]. Disponível em: http://bvssp.cict.fiocruz.br/lildbi/docsonline/get.php?id=281.

25. Secretti T. Distribuição dos homicídios em Porto Alegre, Rio Grande do Sul, 2007: contexto sócio-espacial e fatores determinantes [dissertação]. Porto Alegre: Faculdade de Medicina da Universidade Federal do Rio Grande do Sul; 2009. 